\title{
Air quality impacts of the 2018 Kīlauea eruption
}

\author{
LeVi GOLSTON ${ }^{12 *}$, DA PAN ${ }^{1}$, XUEHUI GUO ${ }^{1}$, NATHAN \\ $\mathrm{LI}^{1}$, RUI WANG ${ }^{1}$, LEI TAO ${ }^{1}$, JAMES MCSPIRITT ${ }^{1}$, EMMA \\ YATES $^{23}$, AND MARK ZONDLO ${ }^{1}$ \\ ${ }^{1}$ Department of Civil and Environmental Engineering, \\ Princeton University, Princeton, NJ, USA \\ ${ }^{2}$ Atmospheric Science Branch, NASA Ames Research \\ Center, Moffett Field, CA, USA (correspondence: \\ levi.m.golston@nasa.gov) \\ ${ }^{3}$ Bay Area Environmental Research Institute, Moffett Field, \\ CA, USA
}

From May to August 2018, residents of the Island of Hawai'i were affected by a major eruption of Kīlauea with activity at the summit and lower East Rift Zone (LERZ). Sulfur dioxide $\left(\mathrm{SO}_{2}\right)$ emissions significantly increased throughout the LERZ, causing localized hazardous conditions and enhanced fine particulate matter $\left(\mathrm{PM}_{2.5}\right)$ downwind, worsening air quality. Here, we analyze multiple available surface network and satellite datasets to better understand the air quality impact of the eruption. Observational data are compared to a Lagrangian transport model, which bridges spatial and temporal gaps to estimate average $\mathrm{SO}_{2}$ and $\mathrm{PM}_{2.5}$ concentrations throughout the island. Orographic influence led to degraded air quality mainly in downwind coastal areas, especially the populated western coast of Hawai'i. During June and July $\mathrm{SO}_{2}$ concentrations in Ocean View (100 km from Fissure 8) exceeded the $75 \mathrm{ppbv}$ 1-hr NAAQS standard $13 \%$ of the time. Also, $\mathrm{PM}_{2.5}$ levels in Ocean View and Kona increased threefold compared to pre-May 2018 conditions. OMI and OMPS column $\mathrm{SO}_{2}$ retrievals showed evidence of an increase in May with relatively constant emissions in June and July. Air quality significantly improved when the eruption winded down in early August, with $<5 \mathrm{ppbv} \mathrm{SO}_{2}$ and $<5 \mu \mathrm{g} \mathrm{m}^{-3} \mathrm{PM}_{2.5}$ reflecting low volcanic emissions. The approach coupling $\mathrm{SO}_{2}$ satellite and ground-based measurements with air quality modeling could be applied to future eruptions, providing more accessible information relevant to specific locations. 